\title{
The Conceptual Framework for the Development of Thailand Economic Animal Traceability System
}

\author{
Suvimol Mukviboonchai ${ }^{1}$, Piya Kovintaweewat ${ }^{2}$, Dech Thammasiri ${ }^{3}$ \\ Nakhon Pathom Rajabhat University, Nakhon Pathom 73000, Thailand \\ E-mail: ${ }^{1}$ suvimol@npru.ac.th, ${ }^{2}$ piya@npru.ac.th, ${ }^{3}$ dech@npru.ac.th
}

\begin{abstract}
Animal traceability is crucial to human health in food safety. It is one of the most concerned issues in developed countries. Animal backgrounds including feeding, decease, medicine, vaccine, health check, movement, and so on, are essential information for customers to ensure the safety of the meat they purchased. Thailand exports economic animals, e.g., swine and poultry, to other countries. Therefore, it is needed to prepare the animal traceability system to support such requirements. This paper presents the conceptual framework for the development of Thailand economic animal traceability system to serve as a guideline to the implementation of food safety in meat supply chain.
\end{abstract}

\section{INTRODUCTION}

Recently, several countries have paid much attention to food safety because it affects their people's healthy and economics. To achieve this, the system that can act quickly when an animal disease event occurs is needed so as to prevent disease spread, protect the health and marketability of their animals, maintain consumer confidence in food supply, and retain access to domestic and foreign markets. Practically, the traceability system consists of three major components, namely, a) a premises identification system, b) an animal identification system, and c) an animal tracing system.

Registering the premises ensures that producers will be notified rapidly when a disease event might impact their area or their animals. Furthermore, it also helps animal health officials locate at-risk animals and take precise actions to address the situation, minimize hardships, and expedite disease eradication efforts as much as possible.

The animal identification system is also a crucial component because it helps identify the animals and also links them to a specific premises. To accomplish this, each animal will be assigned a unique identification number, which is embedded in a device attached with animals. The method of identification or type of identification device varies among species, including ear tags, tattoos, and radio frequency identification devices (RFID) according to ISO 11784 [1].

The last component is the animal tracing system, which contains information about the animal location and movement records needed to help safeguard animal health. This system will enable animal health officials to submit requests for information to the animal identification number device distribution databases and animal tracking databases when investigating an animal disease event. Animal tracing information will provide animal health officials with timely, accurate records that show where animals have been and what other animals have come into contact with them.

Several countries have been deployed the traceability system, including USA, Canada, European Union, Japan, Australia, and so on [2 -6]. Therefore, we believe that this system is also essential to Thailand. However, we are currently in the process of studying the possibility of deploying the traceability system nationwide. In this paper, we explain the fundamental conceptual framework for the development of Thailand economic animal traceability system.

The rest of this paper is organized as follows: After briefly describing some works related to the animal traceability system in Section II, we explain the methodology for developing the animal traceability system for Thailand in Section III. Section IV presents the architecture of the economic animal traceability system. The conceptual design of the economic animal traceability system is given in Section V. Finally, the conclusion is in Section VI.

\section{RELATED WORKS}

Several countries have concerned on animal and meat traceability issues particularly since bovine spongiform encephalopathy (BSE), food and mouth disease (FMD), and avian influenza have spread out [7]. Animal identification and traceability system is an effort to ensure food safety. Below are a summary of the traceability system that is being deployed in USA, Europe Union, and Japan, for instance.

\section{A. USA}

United States Animal Identification Plan was developed by National Identification Development Team to support several species of animals, such as beef, swine, sheep, poultry, aquaculture, and so forth [2]. There are three phases of implementation: premise identification, individual or group/lot identification, and an animal traceability system. Communications, standards, and information systems to support the 48-hour traceback objective were designed.

\section{B. European Union}

European Union requires the member countries to meet the European regislation by proving the capacity to track and trace

\footnotetext{
${ }^{1}$ Computer Technology Program, Faculty of Science and Technology

${ }^{2}$ RFID Technology and Applications Research Unit, Faculty of Science and Technology

${ }^{3}$ Business Computer Program, Faculty of Management Science
} 
all livestock. The system needed to be developed to contain details of identification, registration, movements, health tests, medication, residue monitoring, and welfare. Electronic Data Interchange (EDI) technique was implemented to exchange animal traceability information [8].

\section{Japan}

In 2002, Japan's law requires mandatory traceback for cattle from farm to packing factory. Each cow was identified with an ear tag displaying a unique identification number. Producers must submit animal data, such as date of birth, sex, breed, owner, slaughter date to the "family register" of the domestic herd. In 2003, traceability regulation extended to retail sale. Meat processors, distributors and retailors must submit traceabilty information by individual or lot number [9].

In the retail sale, supermarkets made value-added to their meat products to assure customers confidence by developing an information system for customers to access from computer in meat section area or home computer. Also mobile phone service provides consumers to retrieve the meat backgroud information almost instantly from tho codes on meat product package labels.

\section{MEthodOLOGY}

EU food law defines traceability is the ability to trace and follow a food, feed, food-producing animal or substance through all stages of production, processing and distribution. To propose the conceptual framework for the development of Thailand economic animal traceability system, internal and external traceability need to be concerned. The methodology is as follows. Firstly, the animal traceability systems of other countries, for example, USA, Canada, European Union, Australia, New Zealand, and Japan countries, had been investigated. Secondly, the process of farm feeding, animal movement, slaughterhouse, throughout the meat distribution had been surveyed. Thirdly, the architecture of the economic animal traceability system had been constructed as the framework of the system. Finally, the logical data flow diagram and database of the system had been designed to be the guidelines of the system development. The following two sections explain the architecture and the conceptual design of the economic animal traceability system.

\section{The ARChitecture of the ECONOMIC ANIMAL TRACEABILITY SYSTEM}

The proposed Thailand economic animal traceability system consists of two parts: web application system and web service system as shown in Fig. 1. The World Wide Web (www) technology has been chosen because it is a powerful channel able to reach every customer who wants to trace back through the origin of the meat they purchased, if they just have computers, pocket PCs, or mobile phones to connect to the Internet. Not only just the customers but meat producers, transporters, slaughterhouses, distributors and exporters also can submit related animal and meat traceability information from anywhere in the world.

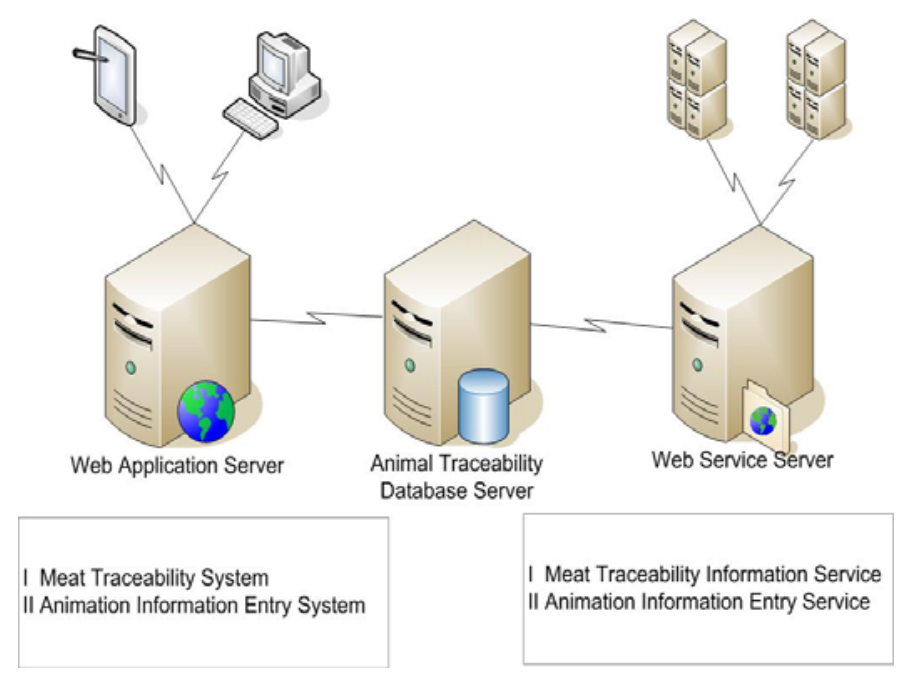

Fig. 1. Animal traceability system architecture.

Web application system is composed of two subsystems, the meat traceability system for customers who want to know the background of the meat, and the economic animal information entry system for the related agents, such as farms, transporters, slaughterhouses, distributors and exporters to submit related information useful for traceability.

Web service technology illustrated in Fig. 2 is designed to support interoperable interaction over a network. Therefore, application software can retrieve or exchage data on remote procedure call format. Web services allow clients and servers communication using XML (Extensible Markup Language) messages that follow SOAP standards. Servers provide WSDL (Web Service Description Language) which is the machine readable description for other application software.

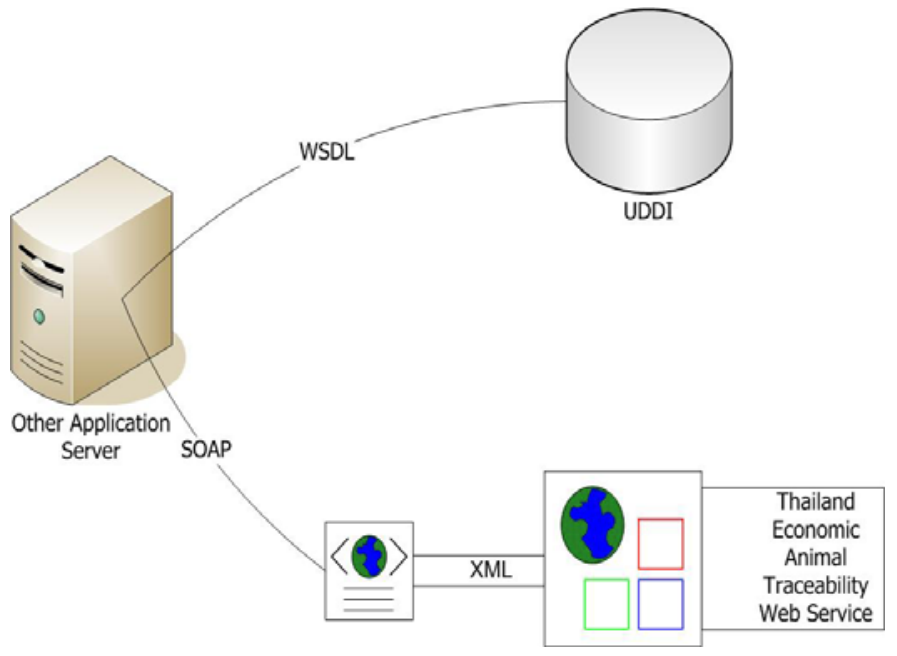

Fig. 2. Animal traceability web service architecture. 
Animal traceability web service system is also designed for two objectives. Firstly, the web service for related agents who need animal traceability information for their own application, for example, supermarkets develop their own application to serve their customers in meat section area to facilitate them in meat traceability. Supermarkets may get tracing back information from this service. Secondly, the web service for agents who need to submit information required to the system. If they have their own application systems, they can export information to the web service regarding to the defined format. This facilitates them in submitting animal information to the animal information entry system directly.

\section{The Conceptual Design of the ECONOMiC ANimAL TRACEABILITY SYSTEM}

This study investigates on economic animals, specifically swine and poultry only, which naturally feed as group in coop or sty. Therefore, a group identification number will be given to a group of them feeding together in the same coop or sty. This group identification number is based on the NECTEC's animal identification recommendation [10]. Animal information will be reported to the traceabilty system since the group identification number has been issued. This group identification number will be used to identify animals through movement, slaughterhouse, and distribution.

The animal traceability database was designed based on the relational data model following all of the related agents and operations. Agents who have to submit animal traceability information to the database are farms, the department of livestock development, veterinarians, animal quarantine stations, slaugtherhouses, food qualification organizations, distributors, and exporters (see Fig. 3).

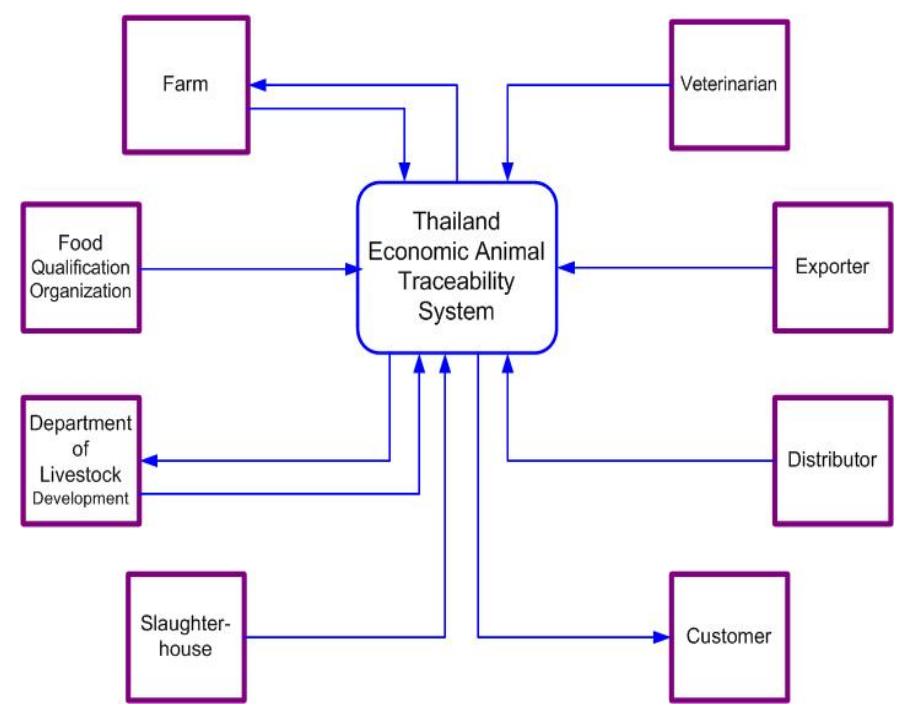

Fig. 3. Context diagram of economic animal traceability system.
- Farms and veterinarian responsibilities are feeding, medication, health checking, and vaccinating information entry.

- Department of livestock development responsibility is group identification generation.

- Animal quarantine station responsibility is animal movement information entry.

- Slaughterhouse responsibities are slaughtering and cutting information entry.

- Food qualification organization responsibility is food qualification checking information entry.

- Distributor and Exporter responsibility is meat distributing information entry.

Thirty two related tables were generated from the conceptual design of the animal traceability database. The table lists are given in Table I. Details of system analysis, such as data flow diagrams, schema of tables, and data elements were described in [11].

TABLE I

LIST OF TABLES OF ANIMAL TRACEABILITY DATABASE

\begin{tabular}{|l|l|l|}
\hline \multicolumn{1}{|c|}{ Table } & \multicolumn{1}{c|}{ Table } & \multicolumn{1}{c|}{ Table } \\
\hline Animal & FoodSubstance & Slaughter \\
\hline Amphur & HealthCheck & Slaughterhouse \\
\hline Barrier & HealthType & SlaughterType \\
\hline Decease & HealthStatus & Species \\
\hline Distribute & MeatCheck & Subdistrict \\
\hline Distributor & MeatCheckType & Transfer \\
\hline Export & MeatStatus & TransferCheck \\
\hline ExportType & Medication & Transporter \\
\hline Farm & Medicine & Unit \\
\hline Feeding & MedicineType & Veterinarian \\
\hline FoodType & Province & \\
\hline
\end{tabular}

Web application system, both the meat traceability system and the economic animal information entry system, can be designed based on the animal traceability database. The economic animal information entry system is for the above parties connecting to the web site passing through the authentification to entry information in their reponsibilities. The meat traceability system widely opens for end customers to trace the meat they purchase back to the farm.

Also, from the animal traceablity database, animal traceability web service system (i.e., meat traceability information service and animal information entry service) were designed. WSDL must be developed as a guideline to interoperate with the web service and registered to UDDI (Universal Description Discovery and Integration) web sites, for example, Thai UDDI registry [12] and UDDI registry for e-Gov [13]. Both are centers of Thailand web service registration. UDDI is the protocol to publish metadata about web services.

Animal traceability database was translated to animal traceability information standard to be facilitated on the web 
service on XML documents which is the universal format. The interoperability standards listed below follow the guideline in developing government information standards, defined by the Ministry of Information Technology and Communication.

- Information collecting in XML document format according to XML naming and design rules defined by UN/CEFACT [14].

- $\quad$ Metadata registries - Naming and identification according to ISO-11179 [15].

- Naming for information interoperability according to ISO15000-5 [16].

The structure of XML documents was predefined in XML schema. For instance, the schema of XML documents for meat traceability information service is shown in Fig. 4.

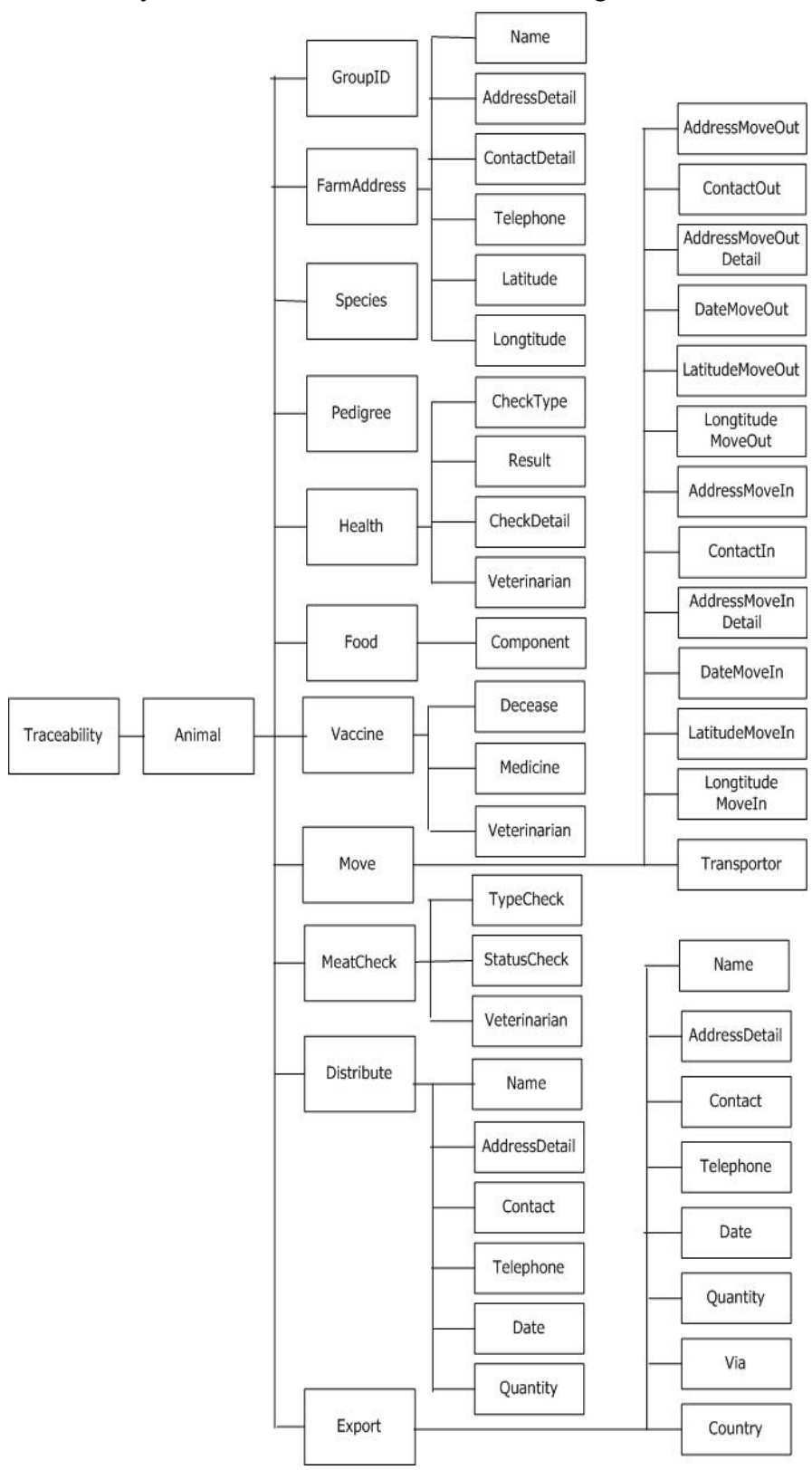

Fig. 4. Animal traceability system web service schema.
Details and example of XML schema and XML documents are expressed in [17].

\section{CONCLUSIONS}

The architecture of Thailand economic animal traceability system is based on web technology. Web application and web services are able to fullfill the requirements of information entry from several parties and information retrieval from customers worldwide. Animal background information and standards identified by organazations in Thailand and international that are related to animal traceability were concerned in system and database design.

\section{ACKNOWLEDGMENT}

The authors thank the RFID program, National Electronics and Computer Technology Center (NECTEC), Thailand, specifically Dr. Chaichana Mitrpant and Dr. Urachada Ketprom, for discussion concerning this work.

\section{REFERENCES}

[1] National Identification Development Team, United States Animal Identification Plan, 2003.

[2] National Animal Identification System (NAIS): A User Guide, November 2006, retrieved from http://animalid.aphis.usda.gov/nais/premises_id/update.shtml.

[3] Canadian livestock traceability backgrounder - Draft for internal review, January 12, 2005, retrieved from http://www.canadaid.com/.

[4] Department for Environment, Food and Rural Affairs, Livestock movements, identification and tracing : Cattle Tracing System, 2007. retrieved from http://www.defra.gov.uk/animalh/id-move/cattle/cts.htm.

[5] Committee on the Guidelines for Introduction of Food Traceability System, Guidelines for introduction of food traceability systems, 2003.

[6] RFIDAA, The National Livestock Identification System (NLIS), 2007, retrieved from: http://www.rfidaa.org/templates/listDetail.jsp?id=96.

[7] E.Napier \& P.Harrop, Food and Livestock Traceability - Forecasts, Needs and Best Practice,. IDTextEX, 2006.

[8] J.McGrann \& H.Wiseman, Animal Traceability across National Frontiers in the European Union, 2001.

[9] R.Clemens, Meat Traceablity in Japan, 2006.

[10] NECTEC, Guidelind to Thailand Animal Identification, report, 2006.

[11] NECTEC, The Proposed Data Standard of Economic Animal Traceability System, unpublished.

[12] Thai UDDI Registry, retrieved from http://thai-uddi.net/uddi/.

[13] UDDI registry for e-Gov, retrieved from http://uddi.mict.go.th

[14] UN/CEFACT. XML Naming and Design Rules version 2.0, 2006.

[15] ISO/IEC, ISO 11179 Metadata Registries Part 5Naming and Identification Principles, 2005.

[16] ISO, ISO/TS 15000-5 2nd Edition Working Draft B, 2006.

[17] NECTEC, The Proposed Data Exchange Standard of Economic Animal Traceability System, unpublished. 